OPEN ACCESS

Edited by:

Tanveer Adyel,

Deakin University, Australia

Reviewed by

Win Colton Cowger, University of California, Riverside,

United States

Simone Lechthaler,

RWTH Aachen University, Germany

*Correspondence:

Tim van Emmerik

tim.vanemmerik@wur.n

tThese authors have contributed equally to this work and share first

authorship

Specialty section:

This article was submitted to

Freshwater Science,

a section of the journal

Frontiers in Environmental Science

Received: 26 October 2021 Accepted: 20 December 2021

Published: 01 February 2022

Citation:

van Emmerik $T$, Vriend $P$ and Copius Peereboom E (2022) Roadmap for Long-Term Macroplastic Monitoring in Rivers.

Front. Environ. Sci. 9:802245. doi: 10.3389/fenvs.2021.802245

\section{Roadmap for Long-Term Macroplastic Monitoring in Rivers}

\author{
Tim van Emmerik ${ }^{1 \times \dagger}$, Paul Vriend ${ }^{1,2 \dagger}$ and Eric Copius Peereboom ${ }^{2}$ \\ ${ }^{1}$ Hydrology and Quantitative Water Management Group, Wageningen University, Wageningen, Netherlands, ${ }^{2}$ Ministry of \\ Infrastructure and Water Management, Directorate-General for Public Works and Water Management, Utrecht, Netherlands
}

Macroplastic pollution in and around rivers negatively impacts human livelihood, and aquatic ecosystems. Monitoring data are crucial for better understanding and quantifying this problem, and for the design of effective intervention strategies. However, current monitoring efforts are often of short duration, or study single river compartments. We present a "Roadmap" to overcome the challenges related to the design and implementation of long-term riverine macroplastic monitoring strategies. This "Roadmap" can help accelerating the process of achieving structural monitoring through providing a stepwise approach, which links monitoring goals and research questions to the data and methods required to answer them. We identify four monitoring goals: 1) policy, 2) knowledge development, 3) operations, and 4) solutions. Linked to these, we provide a non-exhaustive list of 12 globally common research questions that are important to answer to reach these goals. The "Roadmap" takes these questions and links them to development levels of monitoring methods for each river compartment: 1) method development, 2) baseline assessment, and 3) long-term monitoring. At each level, specific questions can only be answered if the level is achieved for specific river compartments. For questions at higher levels, the previous levels need to be achieved first. This creates a clear stepwise approach to solve open challenges. With the "Roadmap", we provide a new tool to support decision-making and planning of specific projects by policy makers. The "Roadmap" is a clear and stepwise, yet flexible framework that allows to add and remove elements based on new insights, available resources, and other relevant changes.

Keywords: litter, water, pollution, data collection, hydrology, marine debris, microplastic, monitoring strategy

\section{INTRODUCTION}

Macroplastic pollution (plastic items $>0.5 \mathrm{~cm}$ ) in riverine environments is an emerging environmental risk, as it negatively impacts ecosystems, endangers aquatic species, and cause economic damage (van Emmerik \& Schwarz, 2020; Meijer et al., 2021). To better quantify riverine macroplastic pollution, and effectively reduce its negative effects, a thorough understanding of sources, transport, fate, and effects of riverine macroplastic pollution is crucial. Macroplastics have been observed in all compartments of the river system (van Emmerik and Schwarz, 2020; MoralesCaselles et al., 2021). Known sources of riverine macroplastic pollution include sewage outlets from wastewater treatment plants, recreational activities in the vicinity of riverbanks, adjacent industrial areas, and areas with high urban activities (Hoellein and Rochman, 2021). Monitoring macroplastic in river systems is crucial to quantify the magnitude of the problem, to identify and quantify inputs from all sources, identify accumulation zones, and to observe temporal trends.

Methods to quantify riverine macroplastic pollution differ per river compartment (e.g., floating, water column, riverbank, sediment, and biota; van Emmerik and Schwarz, 2020) in terms of their 
level of technological readiness. Floating macroplastics and macroplastics on riverbanks have been studied to a greater extent, which has led to these methods to be more developed compared to those for the other compartments. For example, multi-year monitoring strategies for riverbank litter have been carried out in Germany and Netherlands (Kiessling et al., 2019; van Emmerik et al., 2020). Floating macroplastic has been quantified across Europe using the same methodology as presented by the European Union Joint Research Centre in the RIMMEL project (González-Fernández et al., 2021). Other river compartments such as the water column and riverbed are studied less frequent and systematically (Blettler et al., 2018; Vriend et al., 2021). Work has been undertaken to develop and harmonize guidelines for monitoring macroplastic in freshwater environments (e.g., Wendt-Potthoff et al., 2020). However, knowledge on how to convert these efforts into long-term monitoring strategies that integrate multiple river compartments is lacking.

Data gathered through long-term and wide-scale monitoring that includes all river compartments are needed to answer the relevant policy, knowledge, operational, and solution-related questions, that are key to solving the problem of macroplastic pollution. However, a structured approach on how to advance from the current short-term and temporary measurements, to an integrated monitoring strategy for riverine macroplastic is currently missing. In this paper we provide the "Roadmap", which can be used by governments, scientists, and practitioners to structure the development of an integrated monitoring strategy. The ideal strategy is highly dependent on local context such as river typology, available resources and the level of pollution (Vriend et al., 2020a). The "Roadmap" can help develop and implement important longterm monitoring in a faster, more reliable, and cost-effective manner. This framework can further be used to determine what type of monitoring is required to answer specific research questions (Goals for Long-Term River Plastic Monitoring) concerning riverine macroplastic pollution.

\section{GOALS FOR LONG-TERM RIVER PLASTIC MONITORING}

Macroplastic monitoring strategies are often set up with different goals. For example, monitoring projects can be undertaken for knowledge development on riverine macroplastic pollution (Kiessling et al., 2021), to aid the development of policy through identifying frequently found items and possible sources (González-Fernández et al., 2021), and or to guide site selection of intervention strategies (Helinski et al., 2021). We identified four overarching goals for monitoring, these being 1) policy, 2) knowledge development, 3) operations and maintenance, and 4) solutions. These four goals were formulated based on literature, and our own experience with relevant stakeholders from academia, (inter)governmental stakeholders, and practitioners.

\section{Goal 1: Policy Development and Implementation}

The first goal of riverine macroplastic monitoring is to support the development of policy aimed at reducing pollution. There has been an increase in new guidelines and regulations related to plastic litter in aquatic environments, such as the EU Marine Strategy Framework Directive (Galgani et al., 2013), the EU Water Framework Directive (Directive 2000/60/EC), and the EU Single-Use Plastics Directive (Elliott and Thomsom, 2020). Monitoring is necessary to design effective policy aimed at the reduction and mitigation of macroplastic pollution, as well as to determine whether policy goals are achieved. Furthermore, macroplastic monitoring will support the development of item or material specific policies. For example, the persistent occurring of small bottles $(<500 \mathrm{ml})$ during monitoring of macroplastic on land has led to the introduction of deposits on these bottles in Netherlands (van Veldhoven, 2020). As many large rivers are transboundary systems, monitoring has to be done in collaboration with neighboring regions (as shown by Schulz et al., 2013 for monitoring of beach litter in the OSPAR region).

\section{Goal 2: Fundamental Knowledge Development}

The second goal relates to all actions for knowledge development. To date, the understanding of macroplastic sources, sinks, pathways, effects, retention times, degradation, and fragmentation is limited. Such knowledge is crucial for optimizing prevention, mitigation, and reduction strategies. We identify three urgent knowledge gaps that require monitoring. The first gap concerns the limited knowledge on the sources of riverine macroplastic, its distribution throughout river systems and how it may affect source reduction and removal strategies (Helinski et al., 2021). The second knowledge gap considers that most riverine macroplastic items do not reach oceans (Meijer et al., 2021; Tramoy et al., 2021). Finally, understanding the effects of extreme events on the leakage, mobilization, and transport of macroplastic through rivers can support better preventive measures (Roebroek et al., 2021). Fundamental knowledge development on these three knowledge gaps will advance prevention, mitigation, and reduction strategies.

\section{Goal 3: Operations and Maintenance}

Governmental organizations may also include the monitoring of plastic pollution in their responsibility for the operation and maintenance of the public works and waterways, including the maintenance and clean-up of infrastructure such as locks, weirs, and levees (van Emmerik and Vriend, 2021). Operations and maintenance of these assets requires a thorough understanding of the presence and magnitude of possible risks. These risks include damage to, or blockage of infrastructure caused by macroplastic pollution (Honingh et al., 2020). To effectively mitigate these risks, managers require a thorough understanding of the effects macroplastic pollution on the infrastructure they are managing. Such understanding has to be generated through monitoring. 
Goal 4: Solution Design and Implementation Finally, monitoring is important to support the development, implementation and evaluation of best sollutions to prevent, mitigate, and reduce macroplastic pollution in (aquatic) ecosystems. Monitoring provides quantitative data, which allow to assess the efficacy of policy changes such as measures to reduce pollution sources (e.g., consumers, industry, and sewage leakage), improved waste infrastructure, or a specific macroplastic collection strategies such as litter traps. Insights gained from this can then be used to design best practices for macroplastic pollution prevention, mitigation, and reduction. For example, data on plastic loads are needed for site selection for the installation of macroplastic traps and to determine the efficacy of these traps (Tramoy et al., 2019; Helinski et al., 2021). Furthermore, these data can be used to forecast during what periods most litter is expected to be transported and what possible sources for this are (van Emmerik et al., 2019). Effects of targeted policy measures can also be evaluated. Long-term data allow for trend analyses to asses the effect of discouraring or banning specific products on leakage of those products into the (aquatic) environment.

\section{Linking Goals to Research Questions}

Based on these four goals and previously published literature, a non-exhaustive list of 12 universally relevant questions was distilled that can be answered to reach the monitoring goals set out in the previous sections (Table 1). This list includes fundamental questions such as how to measure macroplastic pollution in a specific river compartment. Moreover, it consists of questions that require long-term monitoring, such as how to determine the impact of measures taken to reduce macroplastic. This list can be expanded to include other open research questions that may stem from previously mentioned research goals. The "Roadmap" presented in the next section is a tool to aid the design of monitoring strategies which can answer this full range of questions.

\section{THE "ROADMAP" FOR LONG TERM-MONITORING OF MACROPLASTIC}

The "Roadmap" is a tool that connects any envisioned future river plastic monitoring strategy with the steps that should be taken to reach this and aligns these actions with selected research goals. In this regard the "Roadmap" is inspired by the backcasting principle, which is a tool used in planning to deal with uncertainty of reaching a desired future by tracking back the steps that can be undertaken to reach it (Dreborg, 1996; Holmberg and Robèrt, 2000).

The "Roadmap" is structured around the twelve open questions identified in the previous section using a threelevel framework. In the end, each question is related to data, though at a different level: 1) method development, 2) baseline assessment, and 3) long-term monitoring. The first
TABLE 1 | Overview of research questions that can be answered with a large scale, integrated monitoring strategy for macroplastic pollution in rivers.

\begin{tabular}{|c|c|}
\hline Nr. & Question \\
\hline 1 & How can macroplastic be monitored in each river compartment? \\
\hline 2 & How to determine the plastic mass balance in rivers? \\
\hline 3 & What are the emissions of macroplastic from rivers into the ocean? \\
\hline 4 & What are standard measuring units for each river compartment? \\
\hline 5 & Where are macroplastic accumulation zones in rivers? \\
\hline 6 & What are the sources of riverine macroplastic? \\
\hline 7 & What are the most abundant macroplastic polymers and items? \\
\hline 8 & How is macroplastic distributed over the river compartments? \\
\hline 9 & What are the effects of specific prevention and reduction measures? \\
\hline 10 & What are the long-term trends of riverine macroplastic transport? \\
\hline 11 & What are transport pathways of plastic pollution though river systems? \\
\hline 12 & e role of floods on macroplastic transport in rivers? \\
\hline
\end{tabular}

level (method development) relates to all technical and methodological developments that are the foundation for a suitable monitoring strategy. For example, no standard method is available to monitor macroplastics in the water column (Collas et al., 2021). To answer in depth question for this compartments a standard method first has to be developed. The first step to solving questions for this compartment therefore starts at level one. The second level (baseline) focuses on establishing a baseline measurement, and can include rapid assessments of macroplastic in a specific compartment. Baselines are crucial to get a first sight on the magnitude of the problem and to provide insights for developing the final long-term monitoring protocol (Nurhati and Cordova, 2020). Macroplastic flux can vary more than five orders of magnitude around the world (van Calcar and Van Emmerik, 2019). A rapid assessment will reveal the approximate local pollution level of a river system. Each river may require a specific monitoring strategy, depending on the level of pollution, relevant research questions, and available resources (Vriend et al., 2020a). Finally, the third level relates to the actual longterm monitoring strategy. At this level, questions about trends, and effects of policy changes on the level of pollution can be answered. This is not possible at one of the lower levels. This creates a clear stepwise approach to solve open challenges. For example, to evaluate the effect of measures, insights on all levels are required (method development, baseline assessment, and long-term monitoring). In contrast, specific questions related to methods and protocols remain on the first level.

The presented three-level structure can be used to assess the current and desired state of knowledge of monitoring for specific compartments. Current monitoring strategies for riverine macroplastic may only include the quantification of it on riverbanks, which results in data that can be used to answer research questions for only this compartment (e.g., Kiessling et al., 2019; van Emmerik et al., 2020). In this case, level one 

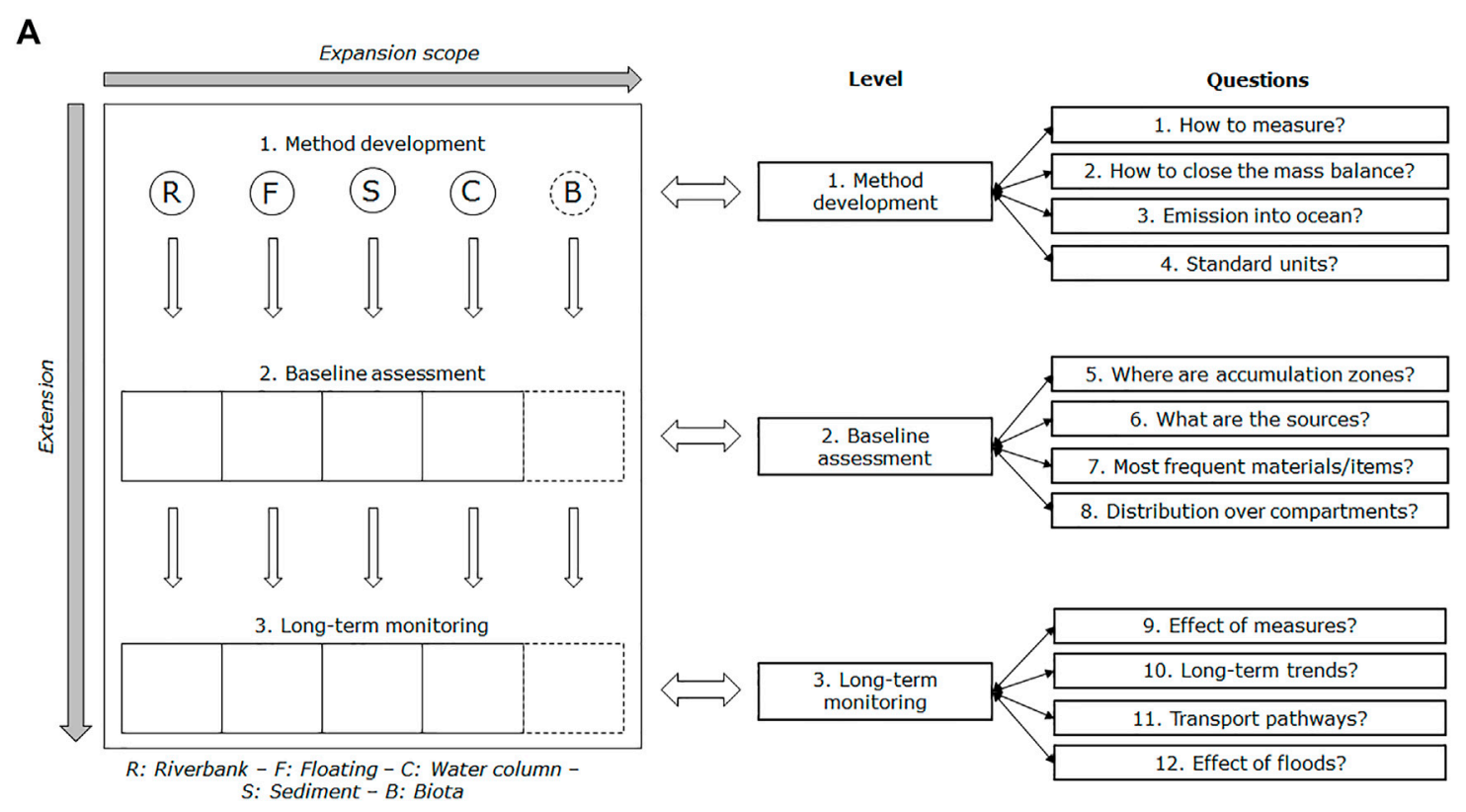

B

\section{Monitoring goals}
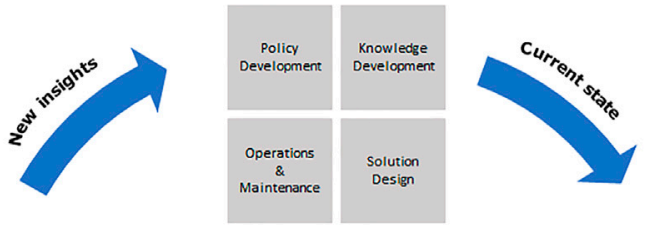

Timeline

\section{Open}

questions
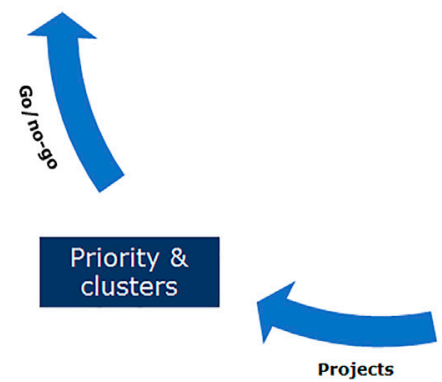

\section{Routes to}

answers

FIGURE 1 | Overview of the "Roadmap" presented in this study, with (A) the "Roadmap" with 3 development levels (Method development, Baseline assessment, and Long-term monitoring) for each river compartment ( $\mathrm{R}=$ Riverbank, $\mathrm{F}=$ Floating, $\mathrm{S}=$ Sediment, $\mathrm{C}=$ Water column, and B = Biota), the level of questions that can be answered for each development level, and the option to expand the scope of monitoring by adding river compartments (dotted line around Biota), and (B) the iterative cycle of the "Roadmap" for long-term monitoring. Adapted from van Emmerik and Vriend (2021), published under a CC BY 4.0 license.

(method development) has been fulfilled since suitable monitoring methods have been developed and tested. Moreover, these methods have been applied at a large scale for both cases, indicating that a first efforts have been made for a baseline. Once the baseline study is finished, the values that are found provide the first statistics on the abundance of riverbank macroplastic pollution, the spatial distribution, and frequently found item types. However, only after the continuation of the monitoring over a longer period of time, the data allow for trend analysis, and observed variations can be attributed to policy measures with a higher degree of confidence.
The "Roadmap" framework is flexible in two dimensions. As discussed, the stepwise approach facilitates extension of the current or future monitoring strategies. Once levels 1 and 2 (method development and baseline assessment) are reached, the strategy can be extended to the next level. The framework also shows how to expand the scope of the strategy by also considering other river compartments besides riverbanks (e.g., floating and water column). Figure 1A shows the result of expanding and extending a strategy. At level 1 (method development), each compartment requires specific technology 
and protocols (e.g., visual counting for floating macroplastics, net sampling for macroplastic in the water column). At the second level (baseline assessment), the compartments form an integrated strategy to allow for a holistic approach for the monitoring protocols, data collection, analysis and dissemination. At the third level (long-term monitoring) the compartments remain connected and integrated for an extended period of time.

The framework allows for a flexible and iterative approach, as individual components can be added, removed, or changed. If a new technology for water column measurements is developed (e.g., echo sounding; Broere et al., 2021), a new "compartment" can be added to the framework. However, here one starts again at level one, as the measurement method needs to be developed, and tested. Another possibility is to add or remove complete river compartments, based on new findings. For example, observations may show that macroplastic in biota is not a relevant compartment for the questions that the monitoring strategy is trying to answer compared to macroplastic on riverbanks and floating macroplastic. As a consequence, the biota "compartment" can be removed from the long-term strategy. Similarly, new compartments (e.g., floodplains) can be added through the expansion of the scope.

\section{Iterative Cycle of Long-Term Monitoring}

The "Roadmap" is not a linear tool. It offers a flexible approach that allows for the incorporation of new insights, monitoring goals, priorities, and data (Figure 1B). Design and optimization of a national riverine macroplastic monitoring strategy requires an iterative approach, the "Roadmap" is therefore designed as an iterative cycle (Figure 1B). First monitoring goals are set and the current state of knowledge is assessed. This leads to the identification of questions cannot be answered yet. The "Roadmap" can then be used to identify the routes that should be taken to develop a fitting monitoring strategy. These routes set out specific projects that should be carried out and the development levels provide guidance on in which order these projects should be executed. After the routes to answers have been finished it can be assessed whether the previously set monitoring goals have been achieved or are still relevant. After this a new cycle can start with new or revised monitoring goals, new open questions, and a new "Roadmap".

\section{CASE STUDY-APPLICATION OF THE "ROADMAP" IN THE NETHERLANDS}

The "Roadmap" is used by Rijkswaterstaat (RWS, Ministry of Infrastructure and Water Management, Directorate-General for Public Works, and Water Management, Netherlands) to advise the Dutch government on the development of a long-term integrated monitoring strategy for riverine macroplastic in the main rivers of Netherlands (Rhine and Meuse; van Emmerik and Vriend, 2021). This case study illustrates how RWS has used the "Roadmap" to plan the long-term monitoring strategy for Dutch rivers.

\section{Monitoring Goals}

Monitoring for policy is important since the Dutch government is in the process of implementing policy to reduce plastic pollution (van Veldhoven, 2020). Data gathered through monitoring can be used to facilitate policy implementation and to monitor the efficacy of measures after implementation. Moreover, monitoring macroplastic pollution for the effective operation and maintenance of waterways and hydraulic infrastructure is important (van Emmerik and Vriend, 2021). Last, RWS has been experimenting with removal technologies through small scale pilots to determine the effectiveness and cost-efficiency of these technologies (van Veldhoven, 2018). Data gathered through monitoring can be used to determine the main sources of pollution that should be reduced and show the efficacy of riverine macroplastic removal technologies.

\section{Open Questions}

The research questions that extend from these goals include:

- How much macroplastic is in the main Dutch waterways?

- What is the composition of macroplastic pollution in relevant river compartments?

- What is the efficacy of measures aimed at reducing riverine macroplastic pollution?

\section{Routes to Answers}

RWS included three river compartments in the first iterative cycle of developing a monitoring strategy: floating macroplastic, macroplastic on riverbanks, and macroplastic suspended in the water column (Figure 2). They made an inventory of the development levels of the monitoring methods for each compartment and used this inventory to decide on the routes required for answers (van Emmerik and Vriend, 2021).

Previous research efforts in Dutch rivers had mainly focused on riverbank macroplastic and on floating macroplastic. Riverbanks had previously been quantified on a large scale for multiple years, though a baseline for RWS was missing (van Emmerik et al., 2020). Floating macroplastic have also successfully been monitored on multiple occasions (e.g., van der Wal et al., 2015; Vriend et al., 2020b), though long term measurements were lacking. Macroplastic in the water column had not yet been quantified, though first tests with trawls, and larvae nets deployed from boats were tested (Collas et al., 2021; Oswald et al., 2021). It was therefore decided that the riverbank compartment and the floating compartment passed development level 1 (method development) and still needed work for passing level 2 (baseline assessment; Figure 2). The water column compartment needed more development to pass level 1 (method development).

\section{Priority and Clusters}

RWS subsequently uses the levels of the compartments to prioritize projects that have to be undertaken to develop a monitoring strategy that can answer their research questions. Methods to quantify macroplastic in the water column are 

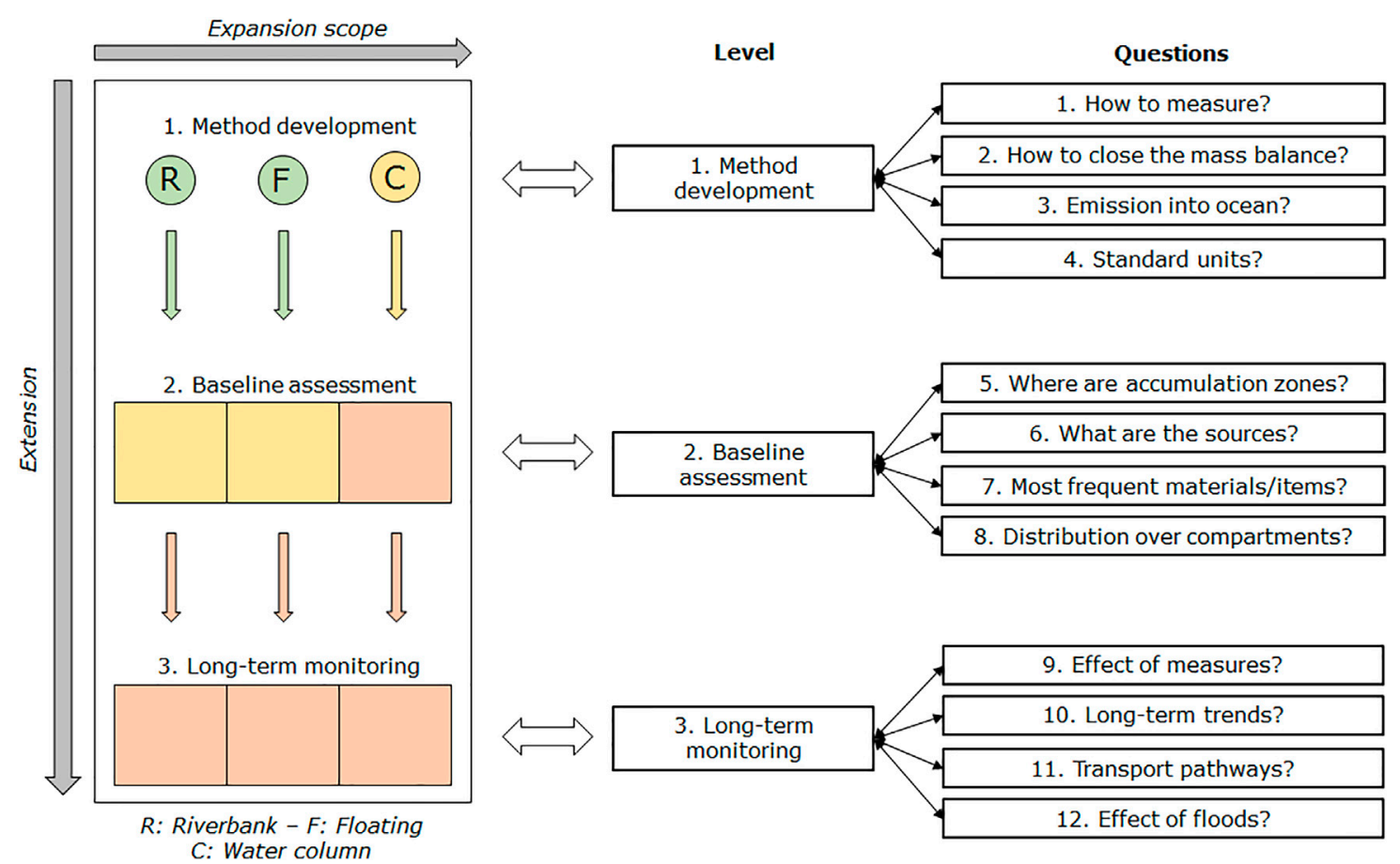

FIGURE 2 | Example in which the "Roadmap" is used to indicate the progress of developing a monitoring strategy by RWS for three river compartments (R = Riverbank, F = Floating macroplastic, and C = Water column). Green indicates the development level has been passed, orange indicates that the development level is in progress, and red indicates the development level has not been started yet since previous levels have not yet been passed. Adapted from van Emmerik and Vriend (2021), published under a CC BY 4.0 license.

relatively underdeveloped. RWS is therefore exploring options to further develop these methods through pilot projects. Besides, baseline measurements are undertaken for floating macroplastics in Netherlands (van Emmerik and de Lange, 2021). Last, the previously developed method for riverbank macroplastic (van Emmerik et al., 2020) is developed further so it can be applied in a standardized way. Once these goals are achieved, the results can be evaluated to determine whether the monitoring goals are being met, or changes need to be made.

\section{CONCLUDING REMARKS}

With the "Roadmap" a practical tool for the design of a national riverine macroplastic monitoring strategy is presented. We emphasize that there is no single solution or path forward. Depending on the defined goals, guidelines and new insights, the actual selection of projects and their respective timelines may change. The "Roadmap" shows what steps are required to arrive at an answer to a specific question.

The "Roadmap" defines four goals for the national riverine macroplastic monitoring strategy: 1) policy development, 2) knowledge development, 3) operations and maintenance, and 4) solutions. A non-exhaustive list of research questions that may stem from these monitoring goals is presented. This list can be expanded by the user of the "Roadmap" to include other open research questions.

The "Roadmap" consists of three levels: 1) method development, 2) baseline assessment, and 3) long-term monitoring. At each level, specific questions can only be answered if the level is achieved for specific river compartments. For questions at higher levels, the previous levels need to be unlocked first. This creates a clear stepwise approach to solve open challenges.

The "Roadmap" can be used by policy-makers to define and prioritize specific projects that are necessary to answer the locally relevant questions. The specific questions and projects are not exhaustive, and the "Roadmap" is a flexible framework that allows to add and remove elements based on new insights, the available resources, and other relevant changes. Riverine macroplastic monitoring remains an iterative process, and with the "Roadmap" we aim to provide a tangible starting point for policy-makers, scientists and practitioners Boonstra et al., 2021, Schmidt et al., 2017.

\section{AUTHOR CONTRIBUTIONS}

TvE conceived the idea, TvE, PV, and EC created the framework, PV prepared the initial draft. All authors wrote the final manuscript. 


\section{FUNDING}

This research was partly funded by the Ministry of Infrastructure and Water Management, DirectorateGeneral for Public Works and Water Management (Rijkswaterstaat), Netherlands. The work of TvE is supported by the Veni research program The River Plastic Monitoring Project with Project Number 18211, which is (partly) financed by the Dutch Research Council (NWO).

\section{REFERENCES}

Blettler, M. C. M., Abrial, E., Khan, F. R., Sivri, N., and Espinola, L. A. (2018). Freshwater Plastic Pollution: Recognizing Research Biases and Identifying Knowledge Gaps. Water Res. 143, 416-424. doi:10.1016/j.watres.2018.06.015

Boonstra, M., van Galen, E., and van Hest, F. (2021). Goed Op Weg Naar Een Schone Noordzee. Utrecht: Stichting De Noordzee.

Broere, S., van Emmerik, T., González-Fernández, D., Luxemburg, W., de Schipper, M., Cózar, A., et al. (2021). Towards Underwater Macroplastic Monitoring Using Echo Sounding. Front. Earth Sci. 9, 628704. doi:10.3389/ feart.2021.628704

Collas, F. P. L., Oswald, S. B., and Verberk, W. C. E. P. (2021). Plastic in de waterkolom van de Boven-Rijn, Waal en IJssel. Nijmegen: Radboud University. Available From: https://puc.overheid.nl/rijkswaterstaat/doc/PUC_644158_31/.

Dreborg, K. H. (1996). Essence of Backcasting. Futures 28 (9), 813-828. doi:10.1016/s0016-3287(96)00044-4

Elliott, T., Gillie, H., and Thomson, A. (2020). “European Union's Plastic Strategy and an Impact Assessment of the Proposed Directive on Tackling Single-Use Plastics Items," in Plastic Waste and Recycling (Academic Press), 601-633. doi:10.1016/b978-0-12-817880-5.00024-4

Galgani, F., Hanke, G., Werner, S., and De Vrees, L. (2013). Marine Litter within the European marine Strategy Framework Directive. ICES J. Mar. Sci. 70 (6), 1055-1064. doi:10.1093/icesjms/fst122

González-Fernández, D., Cózar, A., Hanke, G., Viejo, J., Morales-Caselles, C., Bakiu, R., et al. (2021). Floating Macrolitter Leaked from Europe into the Ocean. Nat. Sustain. 4 (6), 474-483. doi:10.1038/s41893-021-00722-6

Helinski, O. K., Poor, C. J., and Wolfand, J. M. (2021). Ridding Our Rivers of Plastic: A Framework for Plastic Pollution Capture Device Selection. Mar. Pollut. Bull. 165, 112095. doi:10.1016/j.marpolbul.2021.112095

Hoellein, T. J., and Rochman, C. M. (2021). The "plastic Cycle": a Watershed-Scale Model of Plastic Pools and Fluxes. Front. Ecol. Environ. 19 (3), 176-183. doi:10.1002/fee.2294

Holmberg, J., and Robèrt, K.-H. (2000). Backcasting - a Framework for Strategic Planning. Int. J. Sust. Dev. World Ecol. 7 (4), 291-308. doi:10.1080/ 13504500009470049

Honingh, D., van Emmerik, T., Uijttewaal, W., Kardhana, H., Hoes, O., and van de Giesen, N. (2020). Urban River Water Level Increase through Plastic Waste Accumulation at a Rack Structure. Front. Earth Sci. 8, 28. doi:10.3389/ feart.2020.00028

Kiessling, T., Knickmeier, K., Kruse, K., Brennecke, D., Nauendorf, A., and Thiel, M. (2019). Plastic Pirates Sample Litter at Rivers in Germany - Riverside Litter and Litter Sources Estimated by Schoolchildren. Environ. Pollut. 245, 545-557. doi:10.1016/j.envpol.2018.11.025

Kiessling, T., Knickmeier, K., Kruse, K., Gatta-Rosemary, M., Nauendorf, A., Brennecke, D., et al. (2021). Schoolchildren Discover Hotspots of Floating Plastic Litter in Rivers Using a Large-Scale Collaborative Approach. Sci. Total Environ. 789, 147849. doi:10.1016/j.scitotenv.2021.147849

Meijer, L. J. J., van Emmerik, T., van der Ent, R., Schmidt, C., and Lebreton, L. (2021). More Than 1000 Rivers Account for $80 \%$ of Global Riverine Plastic Emissions into the Ocean. Sci. Adv. 7 (18), eaaz5803. doi:10.1126/ sciadv.aaz5803

Morales-Caselles, C., Viejo, J., Martí, E., González-Fernández, D., Pragnell-Raasch, H., González-Gordillo, J. I., et al. (2021). An Inshore-Offshore Sorting System

\section{ACKNOWLEDGMENTS}

We thank Bert Bellert, Frank Collas, and Felipe Moscoso Cruz for their valuable inputs during the writing process. This paper is based on the report Roadmap litter monitoring in Dutch rivers (in English and Dutch), published by Wageningen University and available via: https://doi.org/10.18174/537439/. We thank the User Committee members of The River Plastic Monitoring Project, Marijke Boonstra (Stichting de Noordzee), Ageeth Boos (Rijkswaterstaat), and Nina Raasakka (UNEP) for their valuable input.

Revealed from Global Classification of Ocean Litter. Nat. Sustain. 4 (6), 484-493. doi:10.1038/s41893-021-00720-8

Nurhati, I. S., and Cordova, M. R. (2020). Marine Plastic Debris in Indonesia: Baseline Estimates (2010-2019) and Monitoring Strategy (2021-2025). Mar. Res. Indonesia 45 (2), 97-102. doi:10.14203/mri.v45i2.581

Oswald, S. B., Schoor, M. M., Buschman, F., and Collas, F. P. L. (2021). Macro-and Mesoplastic Abundance and Composition in the Water Column of the River Waal. in Rivers in an Uncertain Future, 38.

Roebroek, C. T. J., Harrigan, S., Van Emmerik, T. H. M., Baugh, C., Eilander, D., Prudhomme, C., et al. (2021). Plastic in Global Rivers: Are Floods Making it Worse. Environ. Res. Lett. 16 (2), 025003. doi:10.1088/1748-9326/abd5df

Schmidt, C., Krauth, T., and Wagner, S. (2017). Export of Plastic Debris by Rivers into the Sea. Environ. Sci. Technol. 51 (21), 12246-12253. doi:10.1021/ acs.est.7b02368

Schulz, M., Neumann, D., Fleet, D. M., and Matthies, M. (2013). A Multi-Criteria Evaluation System for marine Litter Pollution Based on Statistical Analyses of OSPAR beach Litter Monitoring Time Series. Mar. Environ. Res. 92, 61-70. doi:10.1016/j.marenvres.2013.08.013

Tramoy, R., Gasperi, J., Colasse, L., Noûs, C., and Tassin, B. (2021). Transfer Dynamics of Macroplastics in Estuaries - New Insights from the Seine Estuary: Part 3. What Fate for Macroplastics. Mar. Pollut. Bull. 169, 112513. doi:10.1016/ j.marpolbul.2021.112513

Tramoy, R., Gasperi, J., Dris, R., Colasse, L., Fisson, C., Sananes, S., et al. (2019). Assessment of the Plastic Inputs from the Seine Basin to the Sea Using Statistical and Field Approaches. Front. Mar. Sci. 6, 151. doi:10.3389/ fmars.2019.00151

van Calcar, C. J., and Van Emmerik, T. H. M. (2019). Abundance of Plastic Debris across European and Asian Rivers. Environ. Res. Lett. 14 (12), 124051. doi:10.1088/1748-9326/ab5468

van Emmerik, T., and de Lange, S. (2021). Pilot monitoring drijvend zwerfafval en macroplastics in rivieren. Wageningen, the Netherlands: Wageningen University \& Research.

van Emmerik, T., Roebroek, C., De Winter, W., Vriend, P., Boonstra, M., and Hougee, M. (2020). Riverbank Macrolitter in the Dutch Rhine-Meuse delta. Environ. Res. Lett. 15 (10), 104087. doi:10.1088/1748-9326/abb2c6

van Emmerik, T., and Schwarz, A. (2020). Plastic Debris in Rivers. Wiley Interdiscip. Rev. Water 7 (1), e1398. doi:10.1002/wat2.1398

van Emmerik, T., Tramoy, R., van Calcar, C., Alligant, S., Treilles, R., Tassin, B., et al. (2019). Seine Plastic Debris Transport Tenfolded during Increased River Discharge. Front. Mar. Sci. 6, 642. doi:10.3389/fmars.2019.00642

van Emmerik, T., and Vriend, P. (2021). Routekaart Zwerfafvalmonitoring Nederlandse Rivieren. Wageningen, the Netherlands: Wageningen University.

van Veldhoven, S. (2020). Kamerbrief besluitvorming statiegeld flesjes en uitvoering moties blikjes. [Letter of government]. Retrieved from https://www.rijksoverheid. nl/documenten/kamerstukken/2020/04/24/kamerbrief-besluitvorming-statiegeldflesjes-en-uitvoering-moties-blikjes.

van Veldhoven, S. (2018). Kamerbrief Gezamelijke Aanpak Plastic Zwerfafval. [Letter of government]. Retrieved from https://www.rijksoverheid.nl/documenten/ kamerstukken/2018/11/06/gezamenlijke-aanpak-plastic-zwerfafval.

Vriend, P., Hidayat, H., van Leeuwen, J., Cordova, M. R., Purba, N. P., Löhr, A. J., et al. (2021). Plastic Pollution Research in Indonesia: State of Science and Future Research Directions to Reduce Impacts. Front. Environ. Sci. 9, 692907. doi:10.3389/fenvs.2021.692907 
Vriend, P., Roebroek, C. T. J., and van Emmerik, T. (2020a). Same but Different: A Framework to Design and Compare riverbank Plastic Monitoring Strategies. Front. Water 2, 563791. doi:10.3389/frwa.2020.563791

Vriend, P., Van Calcar, C., Kooi, M., Landman, H., Pikaar, R., and Van Emmerik, T. (2020b). Rapid Assessment of Floating Macroplastic Transport in the Rhine. Front. Mar. Sci. 7, 10. doi:10.3389/fmars.2020.00010

Wendt-Potthoff, K., Avellán, T., van Emmerik, T., Hamester, M., Kirschke, S., Kitover, D., et al. (2020). Monitoring Plastics in Rivers and Lakes: Guidelines for the Harmonization of Methodologies. Nairobi, Kenya: United Nations Environment Programme.

Conflict of Interest: The authors declare that the research was conducted in the absence of any commercial or financial relationships that could be construed as a potential conflict of interest.
Publisher's Note: All claims expressed in this article are solely those of the authors and do not necessarily represent those of their affiliated organizations, or those of the publisher, the editors and the reviewers. Any product that may be evaluated in this article, or claim that may be made by its manufacturer, is not guaranteed or endorsed by the publisher.

Copyright () 2022 van Emmerik, Vriend and Copius Peereboom. This is an openaccess article distributed under the terms of the Creative Commons Attribution License (CC BY). The use, distribution or reproduction in other forums is permitted, provided the original author(s) and the copyright owner(s) are credited and that the original publication in this journal is cited, in accordance with accepted academic practice. No use, distribution or reproduction is permitted which does not comply with these terms. 